\title{
Avalanche simulation with SAMOS
}

\author{
Peter SAMPL, ${ }^{1}$ Thomas ZWINGER ${ }^{2}$ \\ ${ }^{1}$ AVL List GmbH, Hans-List-Platz 1, A-8020 Graz, Austria \\ E-mail: peter.sampl@avl.com \\ ${ }^{2}$ CSC - Scientific Computing Ltd, P.O. Box 405, FIN-02101, Espoo, Finland
}

\begin{abstract}
Dry snow avalanches consist of two distinct layers. A dense-flow layer is superposed by a powder-snow layer, a cloud of relatively small ice particles suspended in air. The density of this suspension is one order of magnitude smaller than that of the dense flow. A simulation model for dry avalanches has been developed, based on separate submodels for the two layers. The sub-models are coupled by an additional transition model, describing the exchange of mass and momentum between the layers. The fundamentals of the two-dimensional granular flow model for the dense flow and of the three-dimensional turbulent mixture model for the powder flow are presented. Results of the complete coupled model, SAMOS (Snow Avalanche MOdelling and Simulation), applied to observed catastrophic avalanche events, are discussed, and the prediction of powder-snow pressures acting on a tunnel bridge is briefly described. SAMOS is used routinely for hazard zoning at the Austrian Federal Service for Torrent and Avalanche Control.
\end{abstract}

\section{INTRODUGTION}

The increasing exploitation of alpine regions by tourism, traffic and the power industry exposes human lives, buildings and roads to snow avalanches. Numerical simulations may be used to estimate avalanche hazard zones or to assess the efficiency of planned defence structures such as supporting constructions in potential avalanche-release areas or protective dams in run-out zones. In Austria, the equivalent of $€ 350$ million was spent on such measures between 1949 and 1989 (BMFL, 1989). Dry avalanches occur quite frequently in the Alps, and the catastrophic avalanches in Austria in 1984, 1988 and 1999 were of this type, so they have been the focus of simulation activities in Austria. The most widely used models, such as statistical run-out models (e.g. Lied and Bakkehøi, 1980), which are restricted to avalanche tracks that fit into certain categories, or one-dimensional centre-of-mass models (e.g. Voellmy, 1955), are highly simplified and cannot describe the deformation of the avalanche body. Moreover, the avalanche path has to be prescribed by the user. Therefore, more use has been made in recent years of two- and three-dimensional models based on fundamental fluid mechanics (see, e.g., Gruber and Margreth, 2001). Two- (or higher-) dimensional models (two dimensions tangential to the terrain surface) can predict the avalanche track as well as lateral spreading and run-out distances and thus provide additional validation criteria.

Dry avalanches are assumed to consist of small, noncohesive ice particles. Every avalanche starts as a dense-flow avalanche with flow densities of $100-400 \mathrm{~kg} \mathrm{~m}^{-3}$. Within this dense-flow layer, momentum is transferred by particle contacts and collisions. If the avalanche moves fast enough, particles at the surface of the dense flow are stirred up due to the shear stress induced by the velocity difference to the air above. Small particles may be kept in suspension by turbulence in the air, thus forming a powder-snow layer, which itself is accelerated by gravitation. Within the powder-snow layer, momentum is transferred by the viscosity and turbulence of the air. Direct particle interaction is assumed to be negligible since the snow volume fraction is small, of the order of 0.01 (corresponding to mixture densities up to 5 or $\left.10 \mathrm{~kg} \mathrm{~m}^{-3}\right)$. Since the two layers differ in the nature of their momentum transfer, separate models are used for them in SAMOS (Snow Avalanche MOdelling and Simulation). These separate models are coupled by relations describing the exchange of mass and momentum between the denseflow and suspension layers (Fig. 1).

\section{DENSE-FLOW MODEL}

In the presented model, the dense-flow layer of the avalanche is assumed to behave like a quasi-statically deforming pile of granular material, sliding with velocity $\bar{u}$ on a thin shear layer at its bottom. This approach was developed by Savage and Hutter (1989). The shear layer is mathematically reduced to a boundary condition that relates the normal stress $\sigma^{(\mathrm{b})}$ to the tangential stress $\tau^{(\mathrm{b})}$ at the bottom

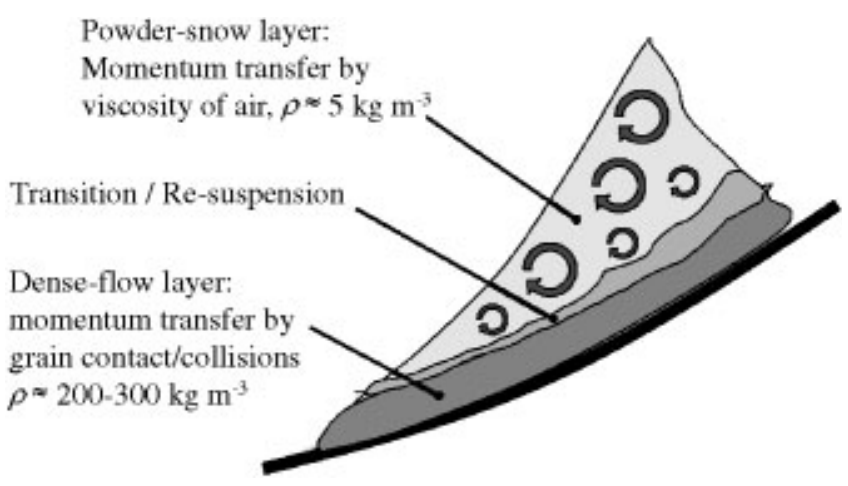

Fig. 1. Dense-flow and powder-snow layers in a dry avalanche. 


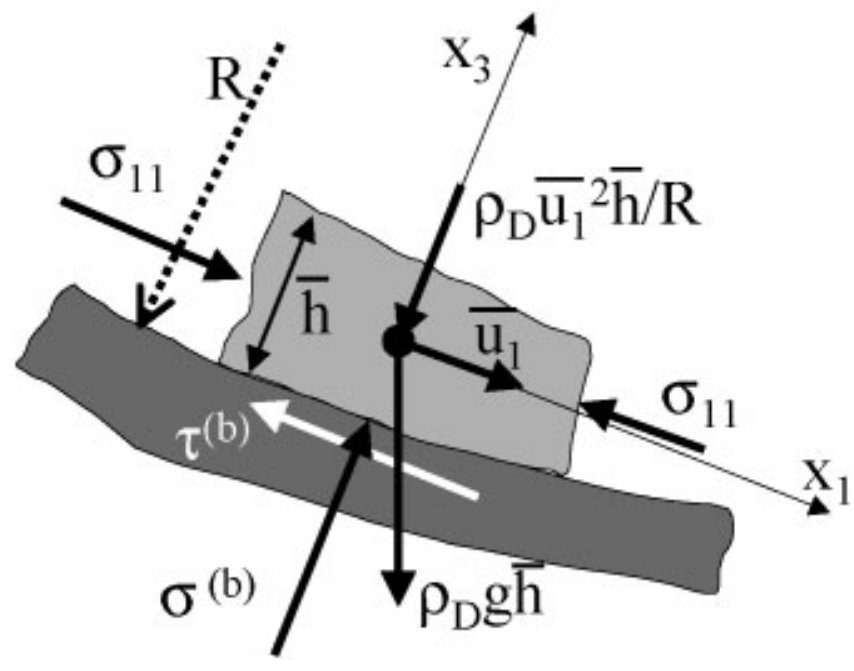

Fig. 2. Lagrangian mass element in the dense-flow layer.

of the dense-flow layer. Within a wide range of strain rates, most granular materials show a constant, rate-independent relation between the exerted normal and tangential stresses (see, e.g., Stadler, 1986). This quasi-static regime is described by a dry Coulombian friction law $\tau^{(\mathrm{b})}=\tan \delta \cdot\left|\sigma^{(\mathrm{b})}\right|$, where $\delta$ denotes the static bed friction angle. On the other hand, the stresses caused by inter-particle collisions dominate in rapidly sheared granular flows, called the "graininertia" regime by Bagnold (1954). The friction then shows a dependence upon the square of the strain rate and hence on the square of the velocity $\bar{u}$. We combine these two limiting regimes in the boundary condition at the bottom by using the larger shear stress of both:

$$
\tau^{(\mathrm{b})}=\max \left(\tan \delta \cdot\left|\sigma^{(\mathrm{b})}\right|, c_{\mathrm{dyn}} \rho_{\mathrm{S}} \bar{u}^{2}\right),
$$

with $\rho_{\mathrm{S}}$ being the mean density in the shear layer and $c_{\mathrm{dyn}}$ an empirically determined model constant. The expression $\tan \delta$ can be related to the $\mu$ value and $c_{\mathrm{dyn}}$ to the $\xi$ value in the Voellmy model, for which a rich literature on empirical values exists (see, e.g., Salm and others, 1990). However, the Voellmy model always adds both stress components. Physically, Equation (1) can be interpreted as an instant change between the two flow regimes at a certain threshold shear rate. The threshold increases with the quasi-static bottom pressure $\sigma^{(\mathrm{b})}$ which mainly results from the weight of the dense-flow layer. As a consequence, shallow avalanches with low density will enter the grain-inertia regime at lower velocities than deep, channelled avalanches. Contrary to earlier numerical implementations of the Savage-Hutter model (e.g. Zwinger, 1996), we apply a finite-volume scheme (see, e.g., Gersten and Herwig, 1992, ch. 5.2.3). The conservation laws of mass and momentum are integrated over a material control volume $V(t)$ that moves with the avalanche (Lagrangian formulation), yielding

$$
\begin{gathered}
\frac{\mathrm{d} V}{\mathrm{~d} t}=\frac{\mathrm{d}(A \bar{h})}{\mathrm{d} t}=-j_{n} A \\
\rho_{\mathrm{D}} \frac{\mathrm{d} u_{i}}{\mathrm{~d} t}=\rho_{\mathrm{D}} g_{i} \\
+\frac{1}{A \bar{H}} \oint_{\partial A}\left\{\int_{b}^{b+\bar{h}} \sigma_{i j} n_{j} \mathrm{~d} x_{3}\right\} \mathrm{d} l-\delta_{i 1} \frac{\tau^{(\mathrm{b})}}{\bar{h}}, i=1,2
\end{gathered}
$$

for a local coordinate system with direction $i=1$ parallel to the velocity vector and direction $i=3$ normal to the terrain surface (Fig. 2). In these relations $\rho_{\mathrm{D}}$ denotes the bulk density of the dense-flow layer, which is assumed to be constant, $\bar{u}_{1}, \bar{u}_{2}$ the velocity components tangential to the terrain surface, $g_{i}$ the acceleration due to gravity, $A$ the base area, $\sigma_{i j}$ the stress tensor (neglecting $\sigma_{12}$; see end of section), $n_{j}$ the lateral surface normal of a volume element $V(t), \bar{h}$ the dense-flow layer height measured normal to the terrain surface, and $\delta_{i j}$ the Kronecker delta (equal to 1 if $i=j$ and 0 if $i \neq j$ ). The mass flux from the dense layer to the powder layer is denoted by $j_{n}$ (see section 4 ). $\partial A$ denotes the boundary line of the base area $A$ of the control volume, and the integrals in the second term on the righthand side of Equation (3) sum up all the forces acting on the lateral boundaries of the volume over the avalanche depth and base area boundary line. $\mathrm{d} l$ is an element of the boundary line. $b$ is the terrain surface coordinate in direction $i=3$. Since the ratio $\alpha$ of the height to the length of the dense-flow layer is very small, terms of order $\alpha^{3 / 2}$ or smaller were dropped after a dimensional analysis of the full equations, according to Savage and Hutter (1989). Equations (2) and (3) provide a system of three differential equations for the three volumeaveraged variables: the tangential velocities $\bar{u}_{1}, \bar{u}_{2}$ and the flow depth $\bar{h}$. The hydrostatic pressure distribution

$$
\sigma_{33}\left(x_{i}, t\right)=\rho_{\mathrm{D}} g_{3}\left(b\left(x_{1}, x_{2}\right)+\bar{h}\left(x_{1}, x_{2}, t\right)-x_{3}\right)
$$

has to be modified for the centripetal acceleration due to the curvature $1 / R=\partial^{2} b / \partial x_{1}^{2}$ of the surface in flow direction (note that direction 1 is always locally chosen to coincide with the flow direction). The pressure at the bottom then reads

$$
\begin{gathered}
\sigma_{33}\left(x_{3}=b\left(x_{1}, x_{2}\right)\right)=\sigma^{(\mathrm{b})} \\
=\rho_{\mathrm{D}}\left(g_{3}-\bar{u}_{1}^{2} \frac{\partial^{2} b\left(x_{1}, x_{2}\right)}{\partial x_{1}^{2}}\right) \bar{h}\left(x_{1}, x_{2}, t\right) .
\end{gathered}
$$

By applying the Mohr-Coulombian bed friction at the bottom, the normal components of the stress tensor at the bottom are related by earth pressure coefficients $K_{(i)}$ :

$$
\begin{gathered}
\sigma_{11}^{(\mathrm{b})}=K_{(1)} \sigma_{33}^{(\mathrm{b})} \\
\sigma_{22}^{(\mathrm{b})}=K_{(2)} \sigma_{33}^{(\mathrm{b})} .
\end{gathered}
$$

The earth pressure coefficients are trigonometric functions of $\delta$ and of the internal friction angle $\phi$ of the granular material, depending on whether the volume element is stretched or compressed (see Zwinger, 2000, for the detailed relations used in SAMOS; earth pressure coefficients have been used in snow avalanche simulations since 1966 (Salm, 1966)). The off-diagonal components are neglected except for $\sigma_{13}^{(\mathrm{b})} \equiv \tau^{(\mathrm{b})}$. It is further assumed that the stresses linearly drop with increasing $x_{3}$ to zero at the free surface. These assumptions are used to determine the integral in Equation (3).

\section{POWDER-SNOW MODEL}

The powder-snow layer of the avalanche is considered a suspension of ice particles in air. This suspension can attain velocities of up to $100 \mathrm{~m} \mathrm{~s}^{-1}$ and flow depths of tens of metres. Reynolds numbers are therefore very high and the flow of the suspension can be regarded as highly turbulent (see, e.g., Scheiwiller and Hutter, 1982; Tesche, 1987). To handle the turbulent flow, the fundamental mass and momentum balances are averaged, as usual in turbulent fluid dynamics: quantities are split into a mean part (indicated by overbars) and a fluctuating part (primed). Density-weighted 
averaging is applied (Favre averaging; cf. Schlichting and Gersten, 1997). After averaging, only the mean variables remain in the linear terms. In the higher-order terms, fluctuation variables remain which are modelled as explained later. A fixed coordinate system is used (Eulerian approach). The averaged mixture density is given by

$$
\bar{\rho}=\rho_{\mathrm{A}}(1-\bar{c})+\rho_{\mathrm{P}} \bar{c},
$$

with $\rho_{\mathrm{A}}$ and $\rho_{\mathrm{P}}$ being the intrinsic densities of air and snow particles, respectively, and $\bar{c}$ the particle volume fraction. Density variations in the air caused by compressibility are neglected. The particles are assumed to move with the same velocity as the air, except for a small, constant settling velocity $u_{\mathrm{S} i}$ of the order of $1 \mathrm{~m} \mathrm{~s}^{-1}$, which is only considered in the particles mass balance to account for sedimentation. The mass balance for the mixture then reads

$$
\frac{\partial \bar{\rho}}{\partial t}+\frac{\partial\left(\bar{\rho} \cdot \bar{u}_{i}\right)}{\partial x_{i}}=0
$$

The snow-particles mass balance

$$
\frac{\partial\left(\rho_{\mathrm{P}} \bar{c}\right)}{\partial t}+\frac{\partial\left(\rho_{\mathrm{P}} \bar{c} \cdot \overline{u_{i}}\right)}{\partial x_{i}}=-\frac{\partial\left(\rho_{\mathrm{P}} \overline{c^{\prime} u_{i}^{\prime}}\right)}{\partial x_{i}}-\frac{\partial\left(\rho_{\mathrm{P}} \bar{c} u_{\mathrm{S} i}\right)}{\partial x_{i}}
$$

includes turbulent dispersion and sedimentation of the particles on the righthand side. Note that the dispersion also accounts for air entrainment as the computational domain includes the air outside the powder cloud. The mixture momentum balance is given by

$$
\begin{array}{r}
\frac{\partial\left(\bar{\rho} \cdot \overline{u_{i}}\right)}{\partial t}+\frac{\partial\left(\bar{\rho} \cdot u_{i} \cdot \overline{u_{j}}\right)}{\partial x_{j}} \\
=-\frac{\partial \bar{\rho}}{\partial x_{i}}+\frac{\partial}{\partial x_{j}}\left(\overline{\tau_{i j}}-\bar{\rho} \cdot \overline{u_{i}^{\prime} u_{j}^{\prime}}\right)+\bar{\rho} g_{i},
\end{array}
$$

with the viscous stresses $\tau_{i j}$ being very small compared to the apparent turbulent stresses $-\bar{\rho} \cdot \overline{u_{i}^{\prime} u_{j}^{\prime}}$. The fluctuation terms containing the primed quantities are modelled according to the widely used k- $\varepsilon$ model (Launder and Spalding, 1972; Rodi, 1980), written for the mixture (Zwinger, 2000). Boundary conditions for velocity and turbulence quantities at the ground and at the interface with the dense-flow avalanche are prescribed by wall functions derived from boundary-layer theory. The interface to the dense-flow layer is assumed to be a rough wall moving with the velocity of the dense flow. Entrainment of snow from the resting snow cover is not considered.

\section{TRANSITION MODEL}

In contrast to the Sl-ld model (Issler, 1998), no detailed model is formulated for the re-suspension/saltation layer. Instead, this layer is collapsed to an interface, and a simple transition model is developed that couples the dense-flow and powder-snow layers by prescribing the transfer of snow mass between the two parts. In the case of neutrally buoyant fine dispersed particles, particle mass transport is approximately analogous to turbulent momentum transport in the boundary layer above the dense-flow surface (Reynolds analogy; Gersten and Herwig, 1992). Parker and others (1986) applied a similar concept to submarine turbidity currents. We adapt this analogy by adding the empirical turbulent Schmidt number $\sigma_{\mathrm{t}}$ to account for the buoyancy of the snow particles and the slip velocity between fluid and particles. Hence, for the particle mass flux normal to the dense-flow surface we write

$$
j_{n}=-\rho_{\mathrm{P}} \frac{\Delta \bar{c}}{\Delta \bar{u}} \frac{\tau_{\mathrm{w}}}{\rho} \frac{1}{\sigma_{\mathrm{t}}},
$$

with the differences between the wall and free stream values (in the sense of boundary-layer theory) $\Delta \bar{u}$ of velocity and $\Delta \bar{c}$ of particle volume fraction. In the equation, $\tau_{\mathrm{w}}$ is the shear stress between the dense-flow and powder-snow layers. We relate the Schmidt number to the size of the suspended snow particles, $d_{\mathrm{p}}$. We use the empirical relation

$$
\sigma_{\mathrm{t}}=\frac{d_{\mathrm{p}}}{d_{\mathrm{ref}}}
$$

with a constant value for $d_{\text {ref. }}$ This yields a mass flux inversely proportional to the particle size, and roughly accounts for the fact that large particles will not follow the air motion closely and are more difficult to re-suspend.

\section{NUMERIGAL IMPLEMENTATION AND APPLICATION}

To solve the Lagrangian dense-flow layer equations (2) and (3), the snow mass is divided into small mass elements, typically 5000-20000. The Voronoi cells (cf. Edelsbrunner, 1987, ch. 13) of the element centre points projected into the $x y$-plane define the geometrical shape of the elements. The Voronoi cells are constructed as a geometric dual of the well-known Delaunay triangulation. Each Voronoi cell is guaranteed to be convex and contains all points in space closer to the corresponding centre point than to any other element centre. A fixed mass is assigned to each moving element (except for the mass transferred to the powder layer), so that mass conservation is guaranteed. To satisfy Equation (2), the flow depth is obtained by dividing the element mass by density and the bottom area of the Voronoi cell. The dense-flow equations are integrated over each cell, and the resulting discretized equation system is solved for a given time-step, using an explicit integration scheme. The bottom wall shear for each element (Equation (1)) is computed with the velocity at the end of the time-step, however, to stabilize the numerical scheme. After that, the element centres are moved according to the calculated velocities. The Voronoi cells are recalculated at each time-step. To obtain a stable solution, the time-step must be chosen so that the moved centre points stay within their original Voronoi cell. (This corresponds to requesting a Courant number below 1 in Eulerian schemes.) Whereas Eulerian schemes use a fixed grid covering the entire avalanche track from the release areas to the deposition areas, the Lagrangian scheme has the advantage that the cells are tied to the avalanche mass and no cells are "wasted" for the area not covered by avalanche mass at a given time-step.

To solve the three-dimensional powder-snow-layer equations $(8-10)$ a standard computational fluid dynamics code (FIRE/SWIFT, developed by AVL Advanced Simulation Technologies; www.avl.com) was adopted. A fixed (Eulerian) grid formed by structured layers of hexahedral volume elements above the terrain surface is used. After discretization according to the finite-volume approach, which guarantees mass conservation, the equation system is iteratively linearized and solved numerically for each time-step by applying the SIMPLE algorithm (Patankar, 1980). The SIMPLE scheme is fully implicit in time and hence is stable for 


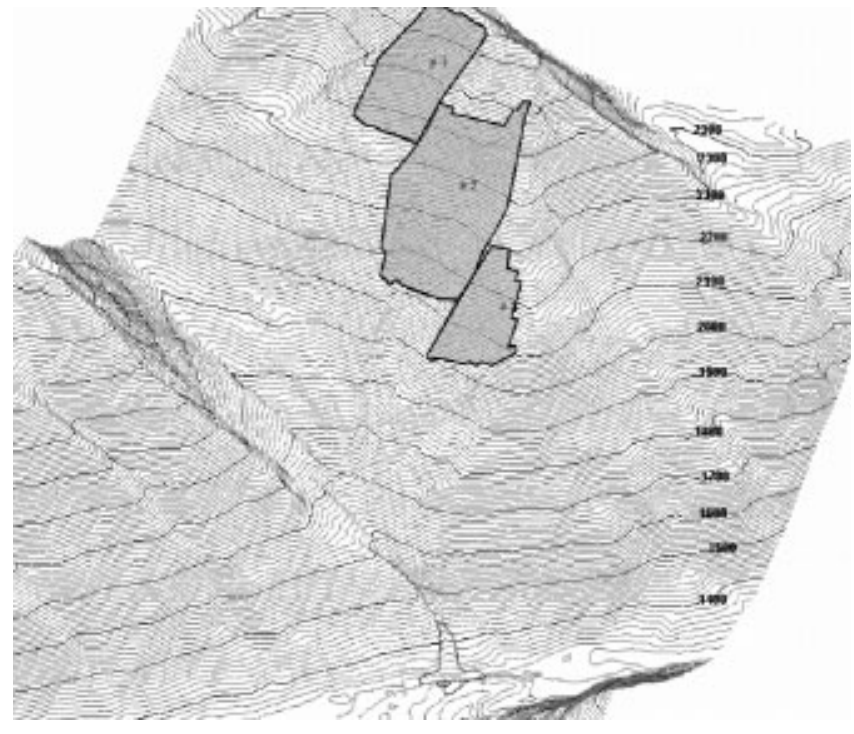

Fig. 3. Madlein 1984: terrain model and release areas.

arbitrarily large time-steps, unless the grid geometry is extremely distorted. For coupled real-scale simulations, a time-step of $0.05 \mathrm{~s}$ for the dense-flow model and of $0.1 \mathrm{~s}$ for the powder model is typically applied, i.e. the dense-flow model performs two sub-steps for one powder step.

Since calculation of the dense-flow part is quasi-two-dimensional, the central processing unit (CPU) time required is mainly determined by the number of nodes in the threedimensional powder avalanche grid. Typically a few hours of CPU time are required on a high-end personal computer. A graphical user interface for importing digital terrain models and specifying input data as well as for post-processing is part of SAMOS. As input for a simulation the following are needed:

a digital terrain model,

the outline of the release areas together with snow depths and densities,

optionally outlines and properties of areas with increased friction (vegetation, etc.),

the density of the flowing dense snow,

the characteristic size of the suspended snow particles, and

numerical parameter as time-steps and spacing for the dense-flow and powder-layer grids.

The same values for all the constants $\left(\delta=16^{\circ}, \phi=35^{\circ}\right.$, $\left.c_{\text {dyn }}=0.022, d_{\text {ref }}=10^{-4} \mathrm{~m}\right)$ in the model are used for all simulation runs, and the user cannot change these values. The friction values are in good agreement with those reported in the Swiss Guidelines (Salm and others, 1990).

\section{RESULTS}

Validation of avalanche simulation models is difficult because high-quality field data are rare and, if available, are often restricted to run-out distances and snow fracture lines in the release area. For a simulation run, all the input data mentioned above must be specified. While a good-quality terrain model is often available, data on the release areas must be extrapolated from fracture lines. Specifically the

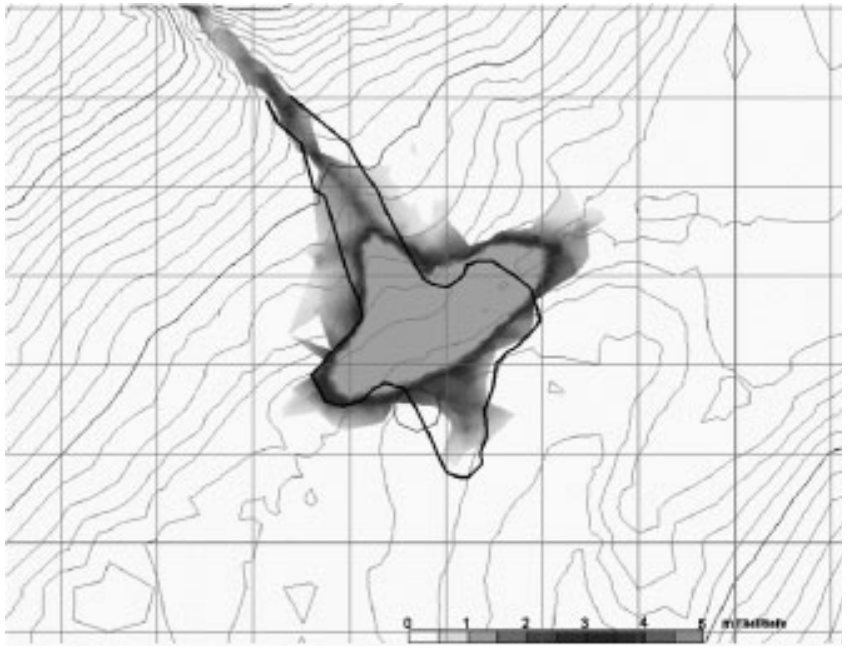

Fig. 4. Madlein 1984: observed (bold line) and computed dense-flow deposition (depth 0-5 $\mathrm{m}$ ); terrain contour line interval $10 \mathrm{~m}$.

lower boundaries of the release areas are determined based on estimation. For a validation, simulations of a few observed recent catastrophic avalanche events in Austria were conducted. Three different calculations are presented briefly.

\subsection{Madlein avalanche, Ischgl, Austrian Tyrol, 1984}

In 1984 the Madlein avalanche killed one person in the village of Ischgl and caused considerable damage. A total snow mass of $76 \mathrm{kt}$ was released at an altitude of $800-1400 \mathrm{~m}$ above the village (the release areas were reconstructed from photographs after the event: Hufnagl, 1988; Hagen, 1997). Figure 3 shows the terrain model (contour lines all $10 \mathrm{~m}$ ) and the release areas. Different snow heights were prescribed for the different areas. Nearly half of the snow mass was suspended during the event, according to the simulation. Figure 4 shows the observed deposition area (bold line; Hufnagl, 1988) and calculated deposition heights (shaded; 0-5 m) of the dense-flow part, which agree fairly well. Raster lines are shown all $100 \mathrm{~m}$, contour lines all $10 \mathrm{~m}$. Figure 5

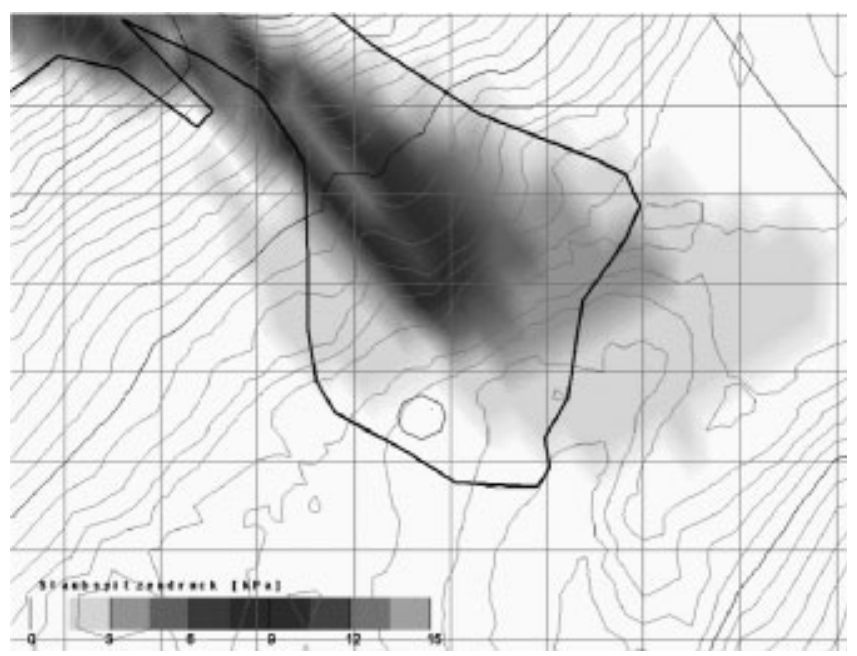

Fig. 5. Madlein 1984: observed (bold line) and computed powder-snow impact area (pressure 0-15 kPa); terrain contour line interval $10 \mathrm{~m}$. 


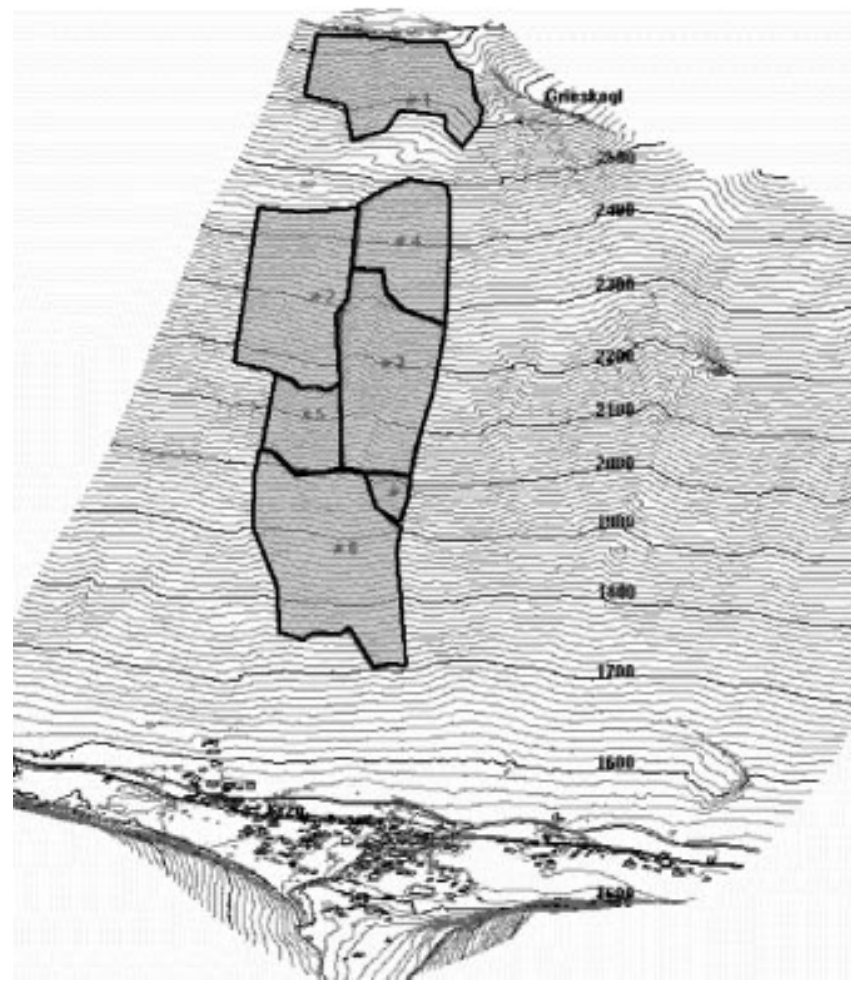

Fig. 6. Galtür 1999: terrain model and release areas.

shows the calculated maximal powder-snow impact pressures $2.5 \mathrm{~m}$ above ground $(0-5 \mathrm{kPa})$ together with the observed area of powder-snow impact (bold line; Hufnagl, 1988). The agreement is not so good as for the dense-flow part. Differences may be due to simplifications in the model and uncertainties in the initial conditions, but one also has to remember that the observations, especially concerning the powder-snow part, are of a qualitative rather than quantitative character.

\subsection{Galtür, Austrian Tyrol, 1999}

In February 1999 a large dry avalanche killed 37 people in the village of Galtür and caused considerable damage. The local snow precipitation during this month amounted to $245 \mathrm{~mm}$ (water value), which was $422 \%$ of the average value in the preceding years. The release area was estimated by the Austrian Federal Service for Torrent and Avalanche Control, Tyrol, based on observations. Including also the meteorological data reported above, an estimated total snow mass of $136 \mathrm{kt}$ was released at an altitude of 300$1300 \mathrm{~m}$ above the village. Figure 6 shows the terrain model (contour lines all $10 \mathrm{~m}$ ) and the outline of the release areas (again with different prescribed snow heights) used for the simulation. The central part of the computed dense flow crosses a road and hits the village, as was observed in reality. The computed pressure at the position of actually destroyed buildings is of the order of $100 \mathrm{kPa}$. Figure 7 shows in detail the computed deposition depths of the dense-flow avalanche mass (scaling $0-5 \mathrm{~m}$ ) together with the outline of the observed deposition zone. The agreement is very satisfactory. Deviations in the vicinity of buildings are to some extent due to their very inaccurate representation in the terrain model. Figure 8 shows computed maximal pressures resulting from the powder-snow part of the avalanche at a height of $2.4 \mathrm{~m}$ above ground (scaling $0-25 \mathrm{kPa}$ ) together

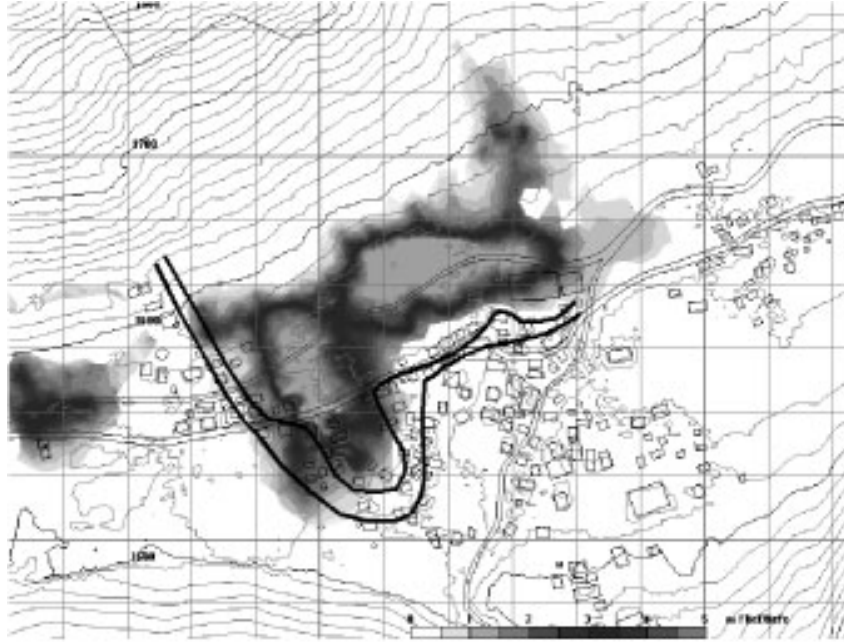

Fig. 7. Galtür 1999: computed (depth 0-5m) and observed deposition (observed deposition outline indicated by inner bold line; outer bold line indicates observed powder-snow impact area).

with the observed zone of powder-snow impact. Computed powder pressures are much lower than dense-flow pressures both in simulation and in reality, but the area affected may be much larger. According to the simulation, 36 t of the total $136 \mathrm{kt}$ of snow released was transferred to the powder-snow part of the avalanche.

\subsection{Evaluation of avalanche effects on a tunnel bridge}

A specific application of the SAMOS model resulted from the need to assess the effect of the powder part of an avalanche on the statics of a tunnel bridge. The tunnel bridge was constructed $40 \mathrm{~m}$ above the bottom of the Gröber avalanche path to improve safety along the Bschlaber access road in Außerfern, Tyrol. The design of the bridge allowed a maximum static load of $20 \mathrm{kPa}$. The simulation was done as if the tunnel bridge had been absent. During the computed impact phase the powder part attained a maximum speed of $70 \mathrm{~m} \mathrm{~s}^{-1}$ with a maximum dynamic pressure $\left(\rho u^{2}\right)$

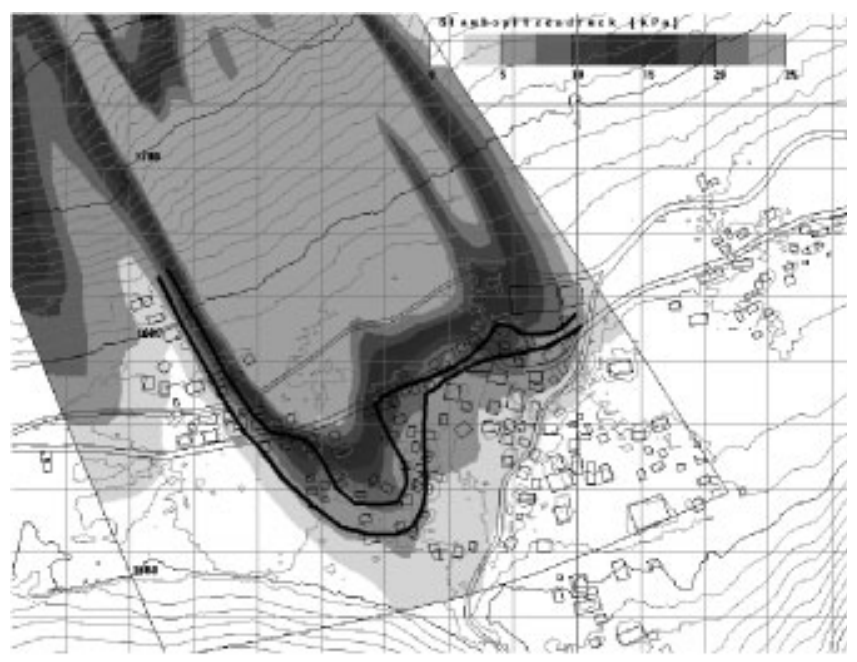

Fig. 8. Galtür 1999: computed (pressure 0-25kPa) and observed powder-snow impact area (observed deposition outline indicated by inner bold line; outer bold line indicates observed powder-snow impact area). 
of $17.5 \mathrm{kPa}$ at the bridge site, which was below the permissible limit. However, since no large avalanche has hit the tunnel bridge yet, a validation was not possible.

\section{CONGLUSION}

The results obtained with the coupled dense-flow-powdersnow model SAMOS show fairly good agreement with observations, if one takes into account the uncertainties in the input data and the simplicity of the transition model used. The model is clearly superior to statistical or onedimensional centre-of-mass models for some uses since it predicts avalanche paths and impact pressures in two and three dimensions, respectively, and treats the dense-flow and powder-snow layers as separate parts. It also allows the assessment of protective constructions such as avalanche dams or retaining walls, as these enter the calculation by modifying boundary conditions (modified terrain model) or initial conditions (reduced release areas). However, simpler models also have their uses since their smaller resource requirements (CPU time, memory) permit extensive parameter studies, probabilistic modelling, etc. SAMOS is used routinely at the Austrian Federal Service for Torrent and Avalanche Control for hazard zoning and for designing defence structures.

The model can be improved by more detailed analysis of the re-suspension zone between the dense-flow and powdersnow layers. The current model does not account for all physical effects (e.g. saltation or hindered settling). A model for erosion of material directly from the resting snow cover has recently been incorporated into SAMOS but needs to be validated. Since a model can only be as good as the experimental or field data it is validated with, the availability of reliable and accurate data from laboratory experiments or real-scale field measurements puts a severe constraint on the development of more advanced avalanche-simulation models.

\section{AGKNOWLEDGEMENTS}

The avalanche simulation model SAMOS was developed for the Ministry for Agriculture and Forestry of Austria, in cooperation with the Austrian Federal Service for Torrent and Avalanche Control and the Institute for Avalanche Research, Innsbruck, Austria. Theoretical investigations and numerical implementations in cooperation with the Technical University of Vienna, Austria, were coordinated and supervised by A. Kluwick. Meteorological data were provided by R. Gabl, Zentralanstalt für Meteorologie und Geodynamik, Wetterdienststelle Innsbruck.

\section{REFERENGES}

Bagnold, R. A. 1954. Experiments on a gravity-free dispersion of large solid spheres in a Newtonian fluid under shear. Proc. R. Soc. London, Ser. A, 225, 49-63.

Bundesministerium für Land- und Forstwirtschaft (BMFL). 1989. Lawinen in Österreich. Wien, Bundesministerium für Land- und Forstwirtschaft.

Edelsbrunner, H. 1987. Algorithms in combinatorial geometry. Heidelberg, etc., Springer. (EATCS Monographs on Theoretical Computer Science 10.)

Gersten, K. and H. Herwig. 1992. Strömungsmechanik. Reihe Grundlagen und Fortschritte der Ingenieurswissenschaften. Braunschweig-Wiesbaden, Vieweg.

Gruber, U. and S. Margreth. 2001. Winter 1999: a valuable test of the avalanche-hazard mapping procedure in Switzerland. Ann. Glaciol., 32, 328-332.

Hagen, G. 1997. Endbericht über das AVL-Staublawinenmodell. Bregenz, Österreichischer Forsttechnischer Dienst für Wildbach- und Lawinenverbauung. Sektion Vorarlberg.

Hufnagl, H. 1988. Ergebnisse einer rechnerischen Auswertung von fünf Lawinen des Katastrophenwinters 83/84. In Internationales Symposium, Interpraevent 1988, Graz, Proceedings. Vol. 3. Klagenfurt, Internationale Forschungsgesellschaft, 227-249.

Issler, D. 1998. Modelling of snow entrainment and deposition in powdersnow avalanches. Ann. Glaciol., 26, 253-258.

Launder, B. E. and D. B. Spalding. 1972. Mathematical models of turbulence. London, Academic Press.

Lied, K. and S. Bakkehøi. 1980. Empirical calculations of snow-avalanche run-out distance based on topographic parameters. F. Glaciol., 26(94), 165-177.

Parker, G., Y. Fukushima and H. M. Pantin. 1986. Self-accelerating turbidity currents. F. Fluid Mech., 171, 145-182.

Patankar, S.V. 1980. Numerical heat transfer and fluid flow. New York, Hemisphere Publishing. (D. Reidel Publishing Co.)

Rodi, W. 1980. Turbulence models and their application in hydraulics. Delft, International Association for Hydraulic Research. (IAHR Special Publication.)

Salm, B. 1966. Contribution to avalanche dynamics. International Association of Scientific Hydrology Publication, 69, (Symposium at Davos 1965 - Scientific Aspects of Snow and Ice Avalanches), 199-214.

Salm, B., A. Burkard and H. Gubler. 1990. Berechnung von Fliesslawinen: eine Anleitung für Praktiker mit Beispielen. Eidg. Inst. Schnee- und Lawinenforsch. Mitt., 47.

Savage, S. B. and K. Hutter. 1989. The motion of a finite mass of granular material down a rough incline. f. Fluid Mech., 199, 177-215.

Scheiwiller, T. and K. Hutter. 1982. Lawinendynamik: Übersicht über experimente und theoretisches Modelle von Fließ- und Staublawinen. Eidg. Tech. Hochschule, Zürich. Versuchsanst. Wasserbau, Hydrol. Glaziol. Mitt. 58.

Schlichting, H. and K. Gersten. 1997. Grenzschicht-Theorie. Heidelberg, etc., Springer.

Stadler, R. 1986. Stationäres, schnelles Fliessen von dicht gepackten trockenen und feuchten Schüttgütern. (Ph.D. thesis, Universität Karlsruhe.)

Tesche, T.W. 1987. Three dimensional dynamic model of turbulent avalanche flow. In ISSW86. A merging of theory and practice. International Snow Science Workshop, 22-25 October 1986, Lake Tahoe, California. Proceedings. Homewood, CA, ISSW Workshop Committee, 111-137.

Voellmy, A. 1955. Über die Zerstörungskraft von Lawinen. Schweiz. Bauztg., 73, 159-165, 212-217, 246-249, 280-285.

Zwinger, T. 1996. Dynamisches Verhalten einer Fließlawine an beliebig geformten Berghängen. (Diplomarbeit, Technische Universität Wien and Technische Hochschule Darmstadt.)

Zwinger, T. 2000. Dynamik einer Trockenschneelawine auf beliebig geformten Berghängen. (Ph.D. thesis, Technische Universität Wien.) 